\title{
ORAL IMPACTS ON DAILY PERFORMANCES(OIDP) SCALE AMONG A GROUP OF EGYPTIAN CHILDREN IN MANSOURA CITY
}

\author{
Salwa M. Awad* and Salwa A. Hegazy**
}

\begin{abstract}
AimTo assess the oral impacts on daily performances (OIDP), and their relationship to dental caries and gingival diseases in an Egyptian sample of Mansoura school children aged 8- 13 years divide into tow age groups.

Methods: A sample of 1200 children were selected on a cross sectional study. The sample was chosen through stratified random sampling within clusters. Children were individually interviewed using the Child-OIDP including the eight-item OIDP frequency scores , and then clinically examined to assess their normative treatment needs for dental caries, and periodontal disease .

Results: A total of 1184 (8-13years) were participated in this study. About $63.5 \%$ of children had oral impacts during the past 3 months. Child-OIDP scores (mean $=7.8 \pm 4.9$ ). Eating was the most reported performance, followed by cleaning teeth and maintaining emotional state in both age groups. Swelling and abscess was the most important perceived causes . Gingival diseases were of less concern in both age groups.
\end{abstract}

Conclusions: problematic eating and toothache were the most common impacts in Egyptian children. These results reflect needs for oral health promotion and treatment of dental caries.

KEY WORDS: Oral health, quality of life, Egyptian children

\section{INTRODUCTION}

Oral health is an integral part of the general health and can affect an individual's life in areas such as language, social, physical and emotional functioning ${ }^{(1)}$. Furthermore, oral diseases can cause serious long-term problems regarding both social and physical health ${ }^{(2)}$.
Despite there is worldwide improvements in people's oral health, it still causing problems in both developed and developing countries. The assessment of oral health status in children and adolescents is important since poor oral health can cause negative effects on learning abilities, growth, socialization and normal daily activities in children ${ }^{(3)}$.

* Assistant Professor of Pediatric Dentistry, Faculty of Dentistery, Mansoura University

** Assistant Professor of Dental Public Health and Preventive Dentistry, Faculty of Dentistery, Mansoura University 
Oral health goals are to promote disease-free mouths that enable people to adequately function in terms of their physical, psychological and social wellbeing. So, its main aim is to achieve a better oral health related quality of life (OHRQoL) ${ }^{(4)}$

The quality of life (QoL) measures were developed to evaluate both the physical and psychosocial impacts of oral health. It aims to quantify the extent to which dental and oral disorders interfere with daily life and well-being together with the outcomes of clinical care, such as the effectiveness of treatment interventions ${ }^{(5,6)}$ The impact of chronic pain on child and family functioning had a widespread interruption in tasks of everyday life (e.g. sleep, schooling, peer relations and physical activity) ${ }^{(7)}$.

Several subjective oral health indicators have been developed. It rang from single item indicators to composite inventories or scoring systems ${ }^{(8)}$. The oral impacts on daily performances (OIDP) inventory was developed to be used in assessing the impacts on individuals' ability to perform daily activities ${ }^{(9)}$. It is a simple and valid instrument, which can be used for assessing oral health needs in population surveys ${ }^{(10)}$.

Quality of life measurement in children involves special methodological problems, such as changes in children's ability to understand at different ages, the difficulty of separating the child's perceptions from the parents and the variation in the number of activities with age ${ }^{(11)}$.

The Child-OIDP was modified to suit children's capability in relation to their intellectual, cognitive, language development, and their memory ability. The sequence of the questions has been modified. The response scales have been simplified. The recall period has been modified to 3 months. ${ }^{(12)}$

In Mansoura city; Egypt, no studies had been conducted regarding oral health related quality of life among children. The aim of this study was to assess the oral impacts on daily performances among a group of schoolchildren using the child OIDP, in addition to assessment of the correlation between the self-rated measures and the mean OIDP scores.

\section{METHODS}

\section{Study population}

The study was approved by the ethical committee of Mansoura University. Permission was also obtained from the education authorities and head teachers for conducting the study. Written informed consents of the pupils' parents were also obtained.

The sample size was determined by the following equation ${ }^{(13)}$

$$
\mathrm{ss}=\frac{\mathrm{Z}^{2 *}(\mathrm{p}) *(1-\mathrm{p})}{\mathrm{d}^{2}}
$$

Ss = sample size

$\mathrm{Z}=\mathrm{Z}$ value (e.g. 1.96 for $95 \%$ confidence level)

$\mathrm{p}=$ percentage picking a choice, expressed as decimal (.5 used for sample size needed)

$\mathrm{d}=$ confidence interval, expressed as decimal (set at level of 0.04)

Twelve primary schools were randomly selected from the eastern and western educational sectors in Mansoura city. About 100 children were selected randomly from each school. A cross-sectional study design was carried out on population of 1200 school children aged 8-13 years. They were divided into two age groups (group 1 aged $8-<11$, and group 2 aged 11-13 years).The sample was chosen through stratified random sampling within clusters technique, given that the pupils are clustered in classrooms according to the WHO $(1997)^{(14)}$ recommendations.

\section{Data collection}

Data were collected using self-administered questionnaires, and clinical oral examinations. One trained and calibrated researcher used a 
self-administered questionnaire based on Arabic translation of Brown and Al-Khayal ${ }^{(15)}$ to collect information about the impact of oral conditions on daily performance during the past 3 months. The questionnaire consisted of 2 parts. The first part included questions regarding the socio-demographic data (age, gender, and the parental educationd ) in addition to the self-reported indicators ( oral health, and oral problems namely toothache, food impaction, gingival diseases, and bad odor). The self-reported oral health were recorded on 5 point scale ranged from 1: excellent to 5 very poor, while oral problems were recorded as present or absent). Perceived oral treatment needs were recorded as existing need no needs, and I don't know.

The second part of the questionnaire was assigned for recording the impacts using the childOIDP index. It assessed the serious oral impacts on eight daily performances namely, eating, speaking, cleaningmouth, relaxing, smiling, studying, emotion and social contact. If a child reported an impact on any of the eight performances, the frequency of the impact was recorded on a scale ranged (from 1-5), where 1 means (affected less than once a month or never) -2 means (once or twice a month), 3 means(once or twice a week), 4 means (3-4 times a week), and 5 means(every day or almost every day). If no impact was reported, then a zero score was assigned.Incomplete questionnaires were excluded.

The oral examinations were conducted by calibrated researchers (intra- and inter-examiner kappa values were 0.88 , and0.91 respectively). All participants were examined for caries experience using DMFT index ${ }^{(16)}$ (caries was diagnosed according to WHO criteria ${ }^{(14)}$, and the gingival condition was assessed using Loe and Sillness gingival index ${ }^{(17)}$ under artificial light using a disposable mouth mirrors and dental probes .

\section{Statistical Analysis}

For child-OIDP, an impact was considered if it was recorded at a moderate or severe level. The number of impacts per person was calculated by the so-called "simple count method ${ }^{(18)}$. The sum of these scores was converted into percentage format. The overall impacts score is the sum of all 8 performances (ranging from 0 to 40 ). Data were analyzed in SPSS, Version 16.0.

\section{RESULTS}

The number of participated children was 1184 . About 16 questionnaires were excluded, (98\% response rate). A total of56 \% of the sample was male. The prevalence of children had oral impacts on their daily life during the last 3 months was $63.5 \%$.

For both age groups, the most prevalent impacts were eating difficulty (44.9\% and 35.6\% for the first and second group respectively)), followed bycleaning teeth ( $(31.4$, and $35.6 \% \% \%$ respectively), then smiling (30.7\%, and $27.3 \%$ respectively. The same variables were also the most reported impacts among males and females (table 1)

The clinical status of the selected children is presented in Table 2. The children were in the mixed dentition stage, with a mean number of the present primary teeth $(8 . \pm 6.1$ and $6.9 \pm 2.4)$ for both age groups. On the other hand, the mean number of the

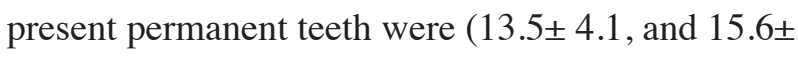
6.2 respectively). They had a low mean DMFT and GI index either for age groups and gender.

The main cause of impacts was swelling and abscess (44\%). Second is mobility of primary teeth $(37.8 \%)$, followed by bad odor $(34.1 \%)$ and malposed teeth $(31 \%)$. However,the least common perceived cause of impacts findings were bleeding gums (13.4\%) and broken teeth(8.1\%). (Fig 1)

The Child-OIDP impact score increased with the decline of the children's oral health status from healthy to unhealthy. The mean Child OIDP score was (2.1) for children who were unsatisfied with their oral health, while for satisfied children it was (13.7). There was a statistical significant difference 
$(\mathrm{P}<0.0001)$. Children who reported no treatment need had a mean OIDP score (4.7), while those reported treatment need had mean OIDP score higher than 19 ( $\mathrm{P}<0.0001)$. The correlation between Child-OIDP and the self-rated oral health (ranged from 17.4 to 3.7 ) was statistically significant $(\mathrm{P}<$ $0.0001)$. (table 3 )
The Child-OIDP scores were correlated to the socio-demographic variables in a predicted manner; the higher the Child-OIDP score was related to gender(9.5) then mother education (9.4). The mean Child-OIDP score in this study was (7.8). (Table 4).

TABLE (1) Prevalence of oral impacts on daily performances (Child-OIDP) in the study sample

\begin{tabular}{|c|c|c|c|c|c|c|}
\hline \multirow{3}{*}{ Variable } & \multicolumn{3}{|c|}{ Age } & \multicolumn{3}{|c|}{ Gender } \\
\hline & Group ( $\mathrm{N}=449)$ & Group 2(N-735) & \multirow{2}{*}{$P$ value } & Males $(\mathrm{N}=672)$ & Females $(\mathrm{N}=512)$ & \multirow{2}{*}{$\mathrm{P}$ value } \\
\hline & $\mathrm{n}$ & $\%$ & & $\%$ & $\%$ & \\
\hline Eating & $202(44.9 \%)$ & $309(42 \%)$ & 0.53 & $280(41.7 \%)$ & $231(45.1 \%)$ & 0.46 \\
\hline Speaking & $49 \quad(10.9 \%)$ & $(8.6 \%) 63$ & 0.23 & $75(11.1 \%)$ & $43 \quad(8.4 \%)$ & 0.15 \\
\hline Cleaning & $141 \quad(31.4 \%)$ & $262(35.6 \%)$ & 0.29 & $220(32.7 \%)$ & $178(34.6 \%)$ & 0.61 \\
\hline Sleeping & $56(12.5 \%)$ & $119(16.2 \%)$ & 0.13 & $75(11.2 \%)$ & $89 \quad(17.4 \%)$ & $0.008 *$ \\
\hline Emotion & $67 \quad(14.9 \%)$ & $92(12.5 \%)$ & 0.3 & $72(10.7 \%)$ & $85 \quad(16.6 \%)$ & $0.01 *$ \\
\hline Smiling & $138(30.7 \%)$ & $201(27.3 \%)$ & 0.35 & $181(26.9 \%)$ & $160(31.3 \%)$ & 0.23 \\
\hline Studying & $16 \quad(3.5 \%)$ & $34 \quad(4.6 \%)$ & 0.39 & $23 \quad(3.4 \%)$ & $26 \quad(5.03 \%)$ & 0.17 \\
\hline Social & $17 \quad(3.8 \%)$ & $40 \quad(5.4 \%)$ & 0.22 & $28 \quad(4.1 \%)$ & $(5.07 \%)$ & 0.48 \\
\hline $\begin{array}{l}\text { At least one } \\
\text { of the above }\end{array}$ & & & & & & \\
\hline
\end{tabular}

TABLE (2) Dental status of the study sample

\begin{tabular}{|c|c|c|c|c|c|c|}
\hline \multirow{2}{*}{ Variable } & \multicolumn{3}{|c|}{ Age } & \multicolumn{3}{|c|}{ Gender } \\
\hline & $\begin{array}{c}\text { Group } 1(n=449) \\
\text { mean } \pm S D\end{array}$ & $\begin{array}{c}\text { Group } 2(\mathrm{n}-735) \\
\text { mean } \pm \mathrm{SD}\end{array}$ & P value & $\begin{array}{c}\text { Males }(n=672) \\
\text { mean } \pm S D\end{array}$ & $\begin{array}{c}\text { Females }(n=512) \\
\text { mean } \pm S D\end{array}$ & $P$ value \\
\hline Number of present primary teeth & $8.2 \pm 6.1$ & $6.9 \pm 2.4$ & $0.00 *$ & $7.3 \pm 5.8$ & $6.7 \pm 4.6$ & 0.054 \\
\hline Dft & $3.1 \pm 1.8$ & $1.9 \pm 1.4$ & $0.00 *$ & $2.7 \pm 0.9$ & $2.1 \pm 1.3$ & $0.001 *$ \\
\hline Number ofpresent permanent teeth & $13.5 \pm 4.1$ & $15.6 \pm 6.2$ & 0.00 & $12.9 \pm 5.8$ & $15.1 \pm 4.6$ & $0.00 *$ \\
\hline Total of DMFT & $0.84 \pm 0.37$ & $0.71 \pm 0.19$ & $0.00 *$ & $0.76 \pm 0.2$ & $0.68 \pm 0.23$ & $0.00 *$ \\
\hline GI index & $0.82 \pm 0.69$ & $0.89 \pm 0.54$ & 0.06 & $0.78 \pm 0.58$ & $0.86 \pm 0.61$ & $0.02 *$ \\
\hline
\end{tabular}




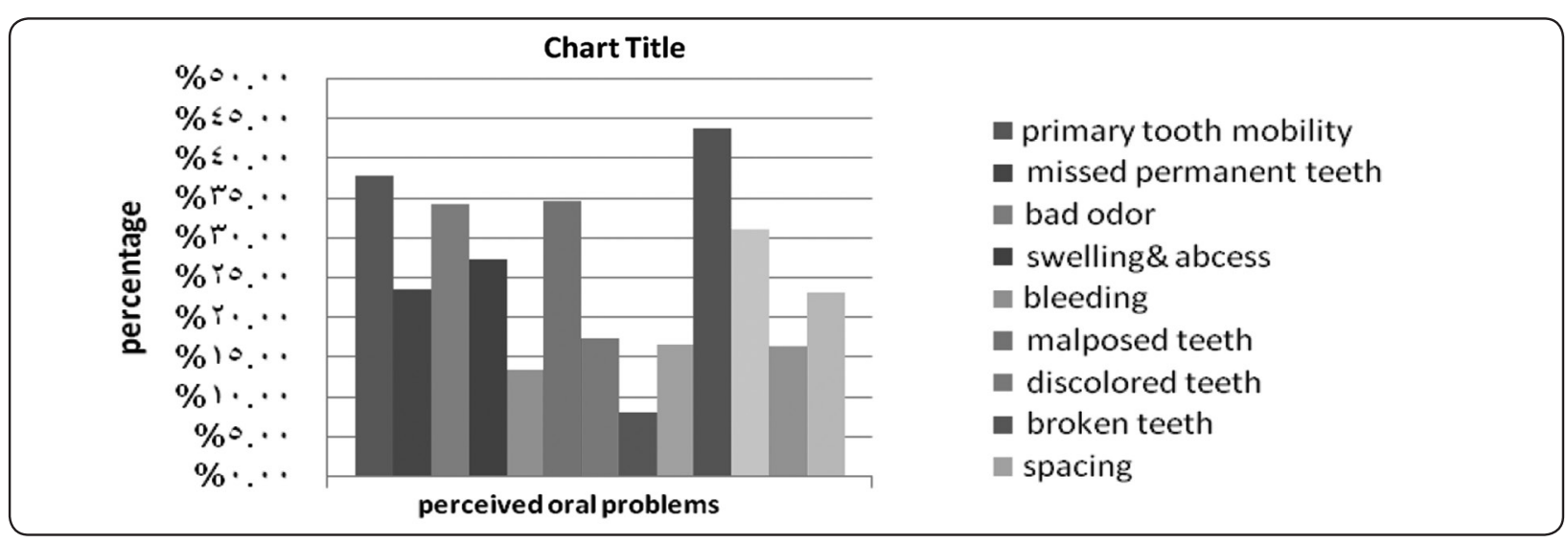

Fig. (1) Perceived oral problems among Egyptian schoolchildren

TABLE (3) Corelation betweenMean child OIDP scores and the self- rated oral health status and needs

\begin{tabular}{|r|r|c|}
\hline \multicolumn{1}{|c|}{ Self-rated measure } & $\begin{array}{c}\text { Mean child } \\
\text { OIDP } \pm \text { SD }\end{array}$ & $\begin{array}{c}\text { Correlation } \mathrm{p} \\
\text { value }\end{array}$ \\
\hline $\begin{array}{r}\text { Satisfaction with oral health } \\
\text { Satisfied }(\mathrm{n}=258)\end{array}$ & $13.7 \pm 7.4$ & $\mathrm{P}=0.001^{*}$ \\
Not satisfied $(\mathrm{n}=926)$ & $2.1 \pm 1.6$ & \\
\hline Perceived oral treatment & & \\
needs & & \\
Existing need $(\mathrm{n}=167)$ & $4.7 \pm 3.1$ & $\mathrm{P}=0.00^{*}$ \\
Do not know $(\mathrm{n}=98)$ & $19.5 \pm 8.4$ & \\
\hline Self-rated oral health & $3.9 \pm 3.2$ & \\
Very poor $(\mathrm{n}=54)$ & $17.4 \pm 9.5$ & \\
Poor $(\mathrm{n}=113$ & $15.9 \pm 9.1$ & $\mathrm{P}=0.002^{*}$ \\
Fair $(\mathrm{n}=378$ & $9.9 \pm 4.8$ & \\
Good $(\mathrm{n}=422$ & $4.6 \pm 1.8$ & \\
Excellent $(\mathrm{n}=217$ & $3.7 \pm 1.1$ & \\
\hline
\end{tabular}

TABLE (4) Corelation of OIDP scores and socio demographic data

\begin{tabular}{|c|c|c|}
\hline Variables & $\begin{array}{c}\text { Mean OIDP } \\
\text { scores } \pm \text { SD }\end{array}$ & p value \\
\hline Age & $7.8 \pm 4.9$ & 0.79 \\
\hline Gender & $9.5 \pm 4.7$ & 0.58 \\
\hline Mother education & $9.4 \pm 2.6$ & $0.00^{*}$ \\
\hline Father education & $8.7 \pm 2.7$ & $0.005^{*}$ \\
\hline
\end{tabular}

\section{DISCUSSION}

The Child-OIDP score was purposefully designed to link the specific oral problems leading to the impacts on quality of life, thereby associating the impacts to the specific oral condition that may need attention ${ }^{(18)}$. This unique characteristic has permitted the Child-OIDP to be used in the assessment of oral health needs as well as in prioritizing dental health care services $^{(19-22)}$. The Child-OIDP is an applicable, short, quick, easy, reliable method that has proved to be a valid measure ${ }^{(12)}$.

The Child-OIDP has been previously studied in a different populations. In this study, the Child-OIDP was conducted on a sample of schoolchildren ( aged 8-13 y) in Egypt (Mansoura city).The translation was based on the validated previous Arabic translation ${ }^{(15)}$. The cross-cultural adaptation was done according the recommendations of Guillemin et $\mathrm{al}^{(23)}$.

The results of this study showed that, eating performance was the most frequently impact in both age and gender groups. It was consistent with previous studies in France and Uganda 23- 25). The next most common impact in Egyptian children referred to difficulties on cleaning teeth and smiling. Females and elderly children more commonly reported difficulties in maintaining usual emotional state and smiling. This might reflect an 
increasing role of psychosocial performances with gender and increasing age ${ }^{(26)}$. The most prevalent impact in Brazilian children was related to difficulty in smiling, laughing and showing teeth without

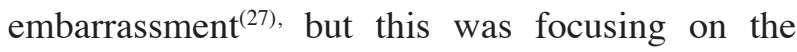
traumatic injuries of anterior teeth study

The prevalence of oral impacts was high, as $63.3 \%$ of the children reported one oral impact at least that affected their daily life in the past 3 months. This is comparable with the results obtained in 11-12-yrold Thai children $(89.8 \%){ }^{(28)}$. However, in France the prevalence observed was higher than in older adolescent populations $(14-16)^{(29)}$. The younger age of the children participated in the present study could explain this higher prevalence. Moreover, it is difficult to compare the prevalence of oral impacts between countries, as the variations can be related to many cultural factors, as already shown in adults ${ }^{(30)}$

Swelling and abscess, mobility of primary teeth, bad odorand malposed teeth were the most commonly reported impacts on daily life.These findings disagree with the study performed in Thailand. The present findings indicate that dental caries and oral ulcers might be important causes of oral impacts among Egyptian adolescents ${ }^{(30)}$.

On the other hand, gingival problems had a minimum effect on the impacts, both in terms of prevalence and scores. This may be due to the young age groups of the children in the present study ${ }^{(31)}$. This results contradict with the results of Bernabe et $\mathrm{al}^{(32)}$ in which the gingival problems were sever and prevalent.

The mean scores of the Child-OIDP in this study was (7.8). It was similar to the mean scores of previous studies that included the same age group; in Uganda it was (8.9) ${ }^{(25)}$; while in France and Sri Lanka it was (6.3 and 7.7 respectively) 24,26$)$.

However, this study faced some limitations where the younger aged children had some difficulties in understanding the purpose of the study and the items of the questionnaire. This was reflected on some difficulties in expressing their problems. To overcome this problem, the researchers explained the questionnaire items clearly. For better understanding changing the pattern of oral impacts throughout the life course, further studies on larger scales are needed.

\section{CONCLUSIONS}

Egyptian children showed high prevalence. Eating, cleaning teeth and smiling were the most commonly reported impacts by both age and gender groups. Swelling and absesses were the most detected cause of oral impacts among the participated Egyptian children. Gingival problems were less prevalent for both age and gender groups. Health promotion, prevention and caries treatment are the main oral health aims in Egyptian children.

\section{REFERENCES}

1. Moynihan PJ. The role of diet and nutrition in the etiology and prevention of oral diseases. Bull Health Organ2005;83: 694-699.

2. Watt GR. Strategies and approaches in oral disease prevention and health promotion. Bull Health Organ 2005; 83: 711-718.

3. Petersen PE. The World Oral Health Report 2003: continuous improvement of oral health in the $21 \mathrm{st}$ century - the approach of the WHO Global Oral Health programme .Community Dent Oral Epidemiol 2003;31(1 Suppl): 3-23.

4. Cohen K, Jago JD. Toward the formulation of sociodental indicators. Int J Health Serv 1976;6:681-687.

5. Awad MA, Locker D, Korner-Bitensky N, Feine JS. Measuring the effect of intra-oral implant rehabilitation on health-related quality of life in a randomised controlled clinical trial. J Dent Res 2000; 79:1659-1663.

6. Allen PF, McMillan AS, Locker D. An assessment of sensitivity to change of the oral health impact profile in a clinical trial. Community Dent Oral Epidemiol 2001; 29: 175-182.

7. Palermo TM. Impact of recurrent and chronic pain on child and family daily functioning: a critical review of the literature. J DevBehavPediatr 2000; 21: 58-69. 
8. Leao A, Sheiham A. The development of a sociodental measure of dental impacts on daily living. Community Dent Health 1996;13:22-26

9. Adulyanon S, Vourapukjaru J, Sheiham A. Oral impacts affecting daily performance in a low dental disease Thai population. Community Dent Oral Epidemiol 1996;24:385-389.

10. Masalu JR, Astrom AN. Applicability of an abbreviated version of the oral impacts on daily performances (OIDP) scale for use among Tanzanian students. Community Dent Oral Epidemiol 2003; 31: 7-14

11. Finlay AY. Quality of life measurement in dermatology: a practical guide. Br J Dermatol 1997; 136: 305-314

12. Gherunpong S, Tsakos G, Sheiham A. Developing and evaluating an oral health-related quality of life index for children; the CHILD-OIDP. Community Dent Health 2004; 21: 161-169.

13. Bartlett, J.E., II; Kotrlik, J.W.; Higgins, C. (2001). "Organizational research: Determining appropriate sample size for survey research". Information Technology, Learning, and Performance Journal 19 (1): 43-50.

14. WHO. Oral Health Surveys: basic methods. Geneva: World Health Organization; 1997.

15. Brown A, Al- Khayal Z. Validity and reliability of the Arabic translation of the child oral-health-related quality of life questionnaire (CPQ11-14) in Saudi Arabia.Int J Pediater Dent 2006; 16: 405-411.

16. Jackson D, James PMC, Slack GL. An investigation into the use of indices devised for the clinical measurement of caries degree. Arch Oral Biol 1963;8(2):55-64.

17. Löe H, Silness J. Periodontal disease in pregnancy. I. Prevalance and severity. ActaOdontolScand 1963;21: 533-551.

18. Allen P, Locker D. Do item weights matter? An assessment using the oral health impact profile. Community Dent Health 1997; 14:133-138.

19. Adulyanon S, Sheiham A. Oral impacts on daily performances. In: Slade GD, editor. Measuring oral health and quality of life. Chapel Hill: University of North Carolina; 1997.

20. Gherunpong S, Sheiham A, Tsakos G. A sociodentalapproach to assessing children's oral health needs: integrating an oral health-related quality of life(OHRQoL) measure into oral health service planning.Bull World Health Organ 2006;84:36-42.
21. Gherunpong S,TsakosG,SheihamA.Asociodentalapproach to assessing dental needs of children:concept and models. Int J Paediatr Dent2006;16:81-8.

22. Gherunpong S, Tsakos G, Sheiham A. A sociodentalapproach to assessing children's orthodontic needs. Eur J Orthod 2006;28:393-9.

23. Guillemin F, Bombardier C, Beaton D. Cross-cultural adaptation of health-related quality of life measures: literature review and proposed guidelines. J ClinEpidemiol 1993; 46: 1417-1432

24. Tubert-Jeannin S, Pegon-Machat E, Gremeau-Richard C, Lecuyer M-M, Tsakos G. Validation of a French version of the Child-OIDP index. Eur J Oral Sci 2005;113:355-62.

25. Astrom AN, Okullo I. Validity and reliability of the Oral Impacts on Daily Performances (OIDP) frequency scale. A cross-sectional study of adolescents in Uganda. BMC Oral Health 2003;3:5-13.

26. Ratnayake N, Ekanayake L. Prevalence and impact of oral pain in 8-year-old children in Sri Lanka. Int $\mathrm{J}$ Paediatr Dent 2005;15:105-12

27. .Ware JE, Brook RH, Davies AR, Lohr KN. Choosing measures of health status for individuals in general populations. Am J Public Health 1981; 71: 620-625

28. Gherunpong S, Tsakos G, Sheiham A. The prevalence and severity of oral impacts on daily performances in Thai primary school children. Health Qual Life Outcomes 2004; 2: 57.

29. Tubert-Jeannin S, Riordan PJ, Morel-Papernot A, Porcheray S, Saby-Collet S. Validation of an oral health quality of life index (GOHAI) in France. Community Dent Oral Epidemiol 2003; 31: 275-284

30. Tsakos G, Marcenes W, Sheiham A. Cross-cultural differences in oral impacts on daily performance between Greek and British older adults. Community Dent Health 2001; 18: 209-213.

31. Bernabe E, Sheiham A, Tsakos G. A comprehensive evaluation of the validity of Child-OIDP: further evidence from Peru. Community Dent Oral Epidemiol 2007;35:1-9.

32. Bernabe E, Krisdapong S, Sheiham A, Tsakos G. Comparison of the discriminative ability of the generic and condition-specific forms of the Child OIDP index: a study on children with different types of normative dental treatment needs.Community Dent Oral Epidemiol 2009; 37: $155-162$. 